\title{
A manhã e o
}

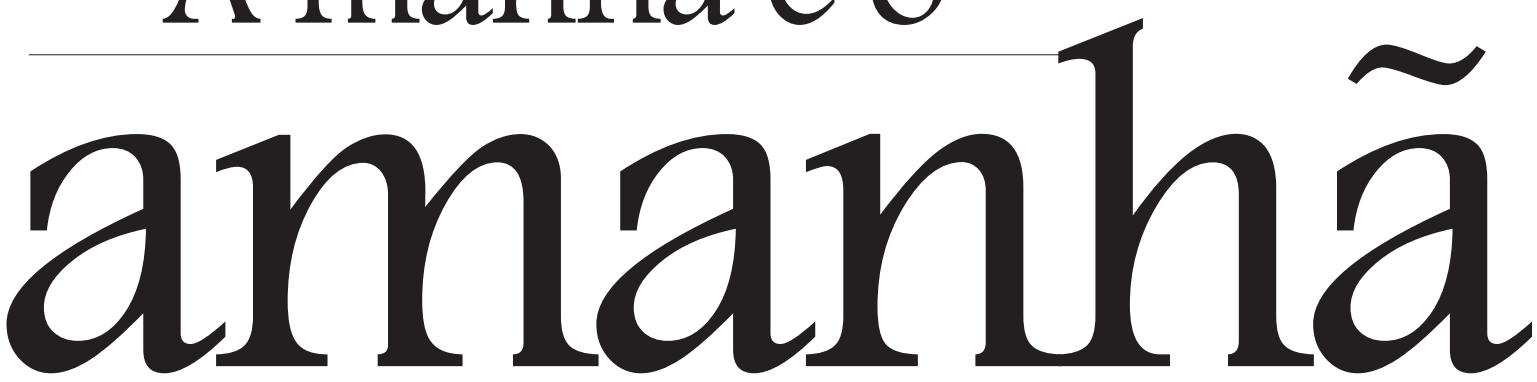

JORGE COLI

\section{"nós. donatários? Caciques?}

\section{Zambis? - Qual! poetas e poetas e poetas e poetas!"}

\section{(Guilherme de Almeida, Raça, 1925)}

JORGE COLI é professor do Departamento de História da Unicamp.

Meninos, Poetas \& Heróis, de Luiza Franco Moreira São Paulo, Edusp, 2001. nosso conhecimento da literatura brasileira do século $\mathrm{XX}$ é desequilibrado e muito mais pobre do que imaginamos. As modas universitárias, movidas tantas vezes por ingenuidades teóricas, as inflexões ideológicas das escolhas intelectuais, sempre, por natureza, parciais e intransigentes, iluminam intensamente alguns focos, tornando cegos outros pontos.

A respeito do livro Meninos, Poetas \& Heróis, de Luiza Franco Moreira, já se as- sinalou um mérito primordial: ele abre novos caminhos. Ao invés de percorrer as pistas incessantemente batidas pela pesquisa do modernismo brasileiro - Mário de Andrade, Oswald de Andrade, Carlos Drummond, Bandeira e alguns outros -, persegue um poeta muito célebre no passado e que hoje se tornou quase apenas um nome nas histórias da literatura e nos manuais: Cassiano Ricardo.

É um livro revelador, pela qualidade da pesquisa que o sustenta. Estimula intensamente o leitor pelas análises que propõe. Provoca uma vontade grande de saber mais, de mergulhar mais nas relações que se entreteciam entre os vários escritores modernos e o que se poderia chamar de espírito de época. Como se trata de um período em que os debates acirrados, as tiranias normativas, a vontade de mudar o mundo, impunham-se a escritores, artistas e intelectuais, o livro enfrenta a delicada junção 
entre política e literatura num caso muito agudo, já que Cassiano Ricardo transformou-se em ideólogo e propagandista do regime de Getúlio Vargas. Com tudo isso, Meninos, Poetas \& Heróis revela-se como indispensável para quem deseja compreender a cultura brasileira daqueles tempos.

A fase mais tardia do poeta encontra-se fora do corpus estabelecido por Luiza Franco Moreira em seu trabalho, consagrado aos vínculos de Cassiano Ricardo com o Estado Novo. Manuel Bandeira, com razão, considerou aquele momento final como o melhor. Contém, de fato, poemas de qualidade muito rara dentro de nossa literatura. Nele, deparamo-nos com uma "Ode Pastoril", incluída em $O$ Arranha-céu de Vidro, de 1956. Eis aqui um trecho:

“Em meu léxico lírico só existem duas palavras, e uma é irmã da outra: a manhã e o amanhã.

Sinto que o espaço é a vida e que o tempo é a morte. E ponho, entre uma e outra, meu rebanho de estrelas".

Estas quadras, depois da leitura de Meninos, Poetas \& Heróis, ecoam de maneira inesperada. Ali, fica declarado que a lírica do poeta só possui duas palavras, carregadas de inícios e promessas, despertares e futuros. É curioso lembrar que a primeira, manhã, havia servido como título para o jornal que centralizou a propaganda escrita do governo Vargas e que foi dirigido por Cassiano Ricardo: A Manhã. E que a segunda, amanhã, era o mote dos governos totalitários no século passado, que se propunham preparar um porvir de felicidade coletiva, quando a humanidade viveria tranqüila e harmoniosa.

Em seguida, Cassiano Ricardo identifica espaço e vida. Trata-se de uma associação que faz, de maneira irresistível, pensar no vitalismo geográfico da "marcha para o oeste”, projeto geopolítico de Vargas, transformado por Ricardo numa pseudo-epopéia, pseudo-história e pseudo-sociologia, intitulada Marcha para o Oeste: a Influência da Bandeira na Formação Social e Política do Brasil, cuja primeira edição data de 1940.

A "Ode Pastoril" não fala disso tudo, em modo direto. Apresenta, antes, um momento íntimo, imobilizado diante de sensações - uma paisagem, um canto de pássaro. Conduz, por sinal, ao balanço entre o instante, o efêmero, sentido como plenitude imóvel, eternizada, e a passagem do tempo, arrastando no seu fluxo a sensação poética da morte. A poesia - o "rebanho de estrelas" - nasce, então, no intervalo entre ambos. Mas a "Ode" abriga palavras queridas do poeta, internas e centrais ao seu processo criador. Elas sinalizam tramas intrincadas, pois o empenho político de Cassiano Ricardo se alimenta da mesma seiva inspiradora que nutriria, mais tarde, a sua poesia mais pessoal e interior.

Luiza Franco Moreira explorou vasos comunicantes tão sutis quanto estes que evoquei, referindo-se ao momento mais público da atuação do poeta. Ela encontrou os fios que se urdem entre a invenção de Martim Cererê, de 1928, a prosa de Marcha para o Oeste, de 1940, e as atividades jornalísticas de Cassiano Ricardo em $A$ Manhã, de 1941 a 1945 . Evoca uma trajetória que migra de um gênero para outro, onde Cassiano Ricardo "move-se da poesia à política no seu sentido mais restrito". Esse percurso fascina por não ser feito de renúncias, nas quais o autor se renegaria a si próprio. Ao contrário, ele avança por coerências que se mantêm e se reforçam.

É uma estranha coisa, os climas "mentais" que, indefinidos para a consciência e para o conceito, profetizam, irmanam-se criando tendências e afinidades, preparando o futuro. Os últimos anos da década de 1920 vêm carregados de convicções nacionalistas e neles explodem manifestações de nacionalidade: é Mário de Andrade com Macunaíma e o Ensaio sobre a Música Brasileira; é Oswald de Andrade, com o “Manifesto Antropofágico”. É Cassiano Ricardo com Martim Cererê.

Muitas vezes separou-se o "bom" do "mau" nacionalismo entre os modernos, 
grosso modo traçando uma linha de demarcação entre esquerda e direita. Menotti del Picchia, Plínio Salgado, Cassiano Ricardo, a "Anta" e os "Verdamarelos" ficaram marcados pela infâmia ideológica. Outros nacionalistas, de posições mais aceitáveis, salvaram-se. Meninos, Poetas \& Heróis não avança pelas inter-relações efetivas que se puderam estabelecer entre os nacionalismos - de qualquer jeito, sempre nefandos - "bons" e "maus". Porém, permite perceber que um estudo dessas afinidades seria muito bem vindo, tanto para uma compreensão complexa de um campo onde o maniqueísmo se dá, de fato, apenas no foco estreito das polêmicas do tempo, quanto no desmonte das mitologias interpretativas, construídas com a herança dessas mesmas polêmicas.

Os anos que precedem a tomada de poder por Getúlio Vargas aferventam desejos de identidade nacional e contêm já algo que está por vir a ser. Luiza Franco Moreira demonstra o quanto, em Martim Cererê, germinava a Marcha para o Oeste, o quanto um estava já no outro, da mesma maneira pela qual Cassiano Ricardo encontrava-se já, mesmo quando ainda não sabia, dentro da ideologia de um Estado Novo que ainda não surgira. Ou melhor, ela mostra de que maneira se fundiam projetos ideológicos individuais e coletivos, um fabricando o outro, um reforçando o outro, premonições e plenitudes amalgamando-se, intervertendo-se.

A atração do poder centralizador, totalitário, foi, muitas vezes, irresistível para os intelectuais. Um tal poder permitiu que eles se imbuíssem de um profético projeto civilizador, impondo diretrizes fundadas em confianças e certezas, fortemente banhadas na eloqüência. É o cunho emotivo que permite ao poeta tornar-se ideólogo: ele convence pela força sentimental ou expressiva das palavras. Mais do que a secura teórica, a poesia veicula convicções coletivas, cria indizíveis - e, está claro, execrandos - sentimentos de identidade, faz com que cada um sinta que olugaronde se encontraé aquele ao qual pertence, e que os caminhos que lhe traçaram são os verdadeiros.

Cassiano Ricardo, em Marcha para o
Oeste, determina o papel para os escritores brasileiros. Vale a pena transcrever aqui uma passagem, que Luiza Franco Moreira retoma em seu livro:

"Ora, ninguém desconhece que a coisa mais grave do atual momento é o exercício da inteligência. A inteligência vadia, enamorada de si mesma, querendo apenas satisfazer a uma vaidade própria, devia ser e foi substituída por outra, já compenetrada de sua função social. Mas não basta isso. É preciso que esta função social da inteligência se exerça num sentido de utilidade nacional, não sendo pouco os deveres que a incumbem e a dignificam. Antes de tudo, o escritor brasileiro tem que ser brasileiro e não será preciso explicar a significação desse dever primordial - pois só poderá interessar ao mundo uma obra de pensamento e de cultura que mergulhe as suas raízes na originalidade de cada estilo de vida, isto é, na intimidade humana e social de cada povo.

Cumprir, aliás, a obrigação de ser brasileiro é realizar o escritor a primeira condição para ser universal. Só depois que se nacionaliza, diz Gide, é que uma literatura toma seu lugar no mundo. Nenhuma violência cometerá o Estado em exigir da inteligência brasileira o cumprimento de uma simples obrigação para consigo mesma. Nesse ponto, como em mais alguns, qualquer restrição à liberdade intelectual será benéfica”.

Este trecho possui um aspecto impressionante: sem a assinatura, poderia ser atribuída, ponto por ponto, a Mário de Andrade. Nele encontra-se a ordem para uma inteligência “útil”, que Mário de Andrade assumiria várias vezes nos anos de 1940, particularmente nos ensaios sobre Debussy, contidos em $O$ Mundo Musical. Nele está também a exigência de uma "utilidade nacional", que Mário de Andrade desenhara com firmeza no Ensaio sobre a Música Brasileira, enunciando ali a característica cuja formulação é atribuída por Cassiano Ricardo a Gide: o artista deve ser, primeiro, nacional, para, depois, atingir o univer- 
sal. Enfim, mesmo a restrição à liberdade intelectual será proposta por Mário de Andrade em seus textos sobre Shostakovich e a música soviética. Isso não quer dizer que Mário de Andrade e Cassiano Ricardo estivessem no mesmo barco: pouco importa, nesse caso, de que rochedo venha o canto da sereia, pois ele ecoa por sobre águas muito turvas, que se irmanam.

Dessas águas turvas desprende-se, hoje, um cheiro ao mesmo tempo asqueroso e sufocante, requentadas que elas foram por um sol falso de promessas futuras. E já que o livro de Luiza Franco Moreira nos demonstra a necessidade de ampliar nossa freqüentação dos poetas brasileiros do século XX, não resisto em transcrever uma das raras reações - pelo menos no meu conhecimento - ao autoritarismo artístico daqueles tempos. Ribeiro Couto, suave, delicado, cidadão do mundo, ironiza diante das receitas para uma brasilidade criadora, como podiam propor Cassiano Ricardo ou Mário de Andrade, num poema publicado no livro Dia Longo, de 1944:

\section{“A Invenção da Poesia Brasileira}

Eu escutava o homem maravilhoso, O revelador tropical das atitudes novas O mestre das transformações em caminho:

'-É preciso criar a poesia deste país de sol! Pobre da tua poesia e da dos teus amigos, Pobre dessa poesia nostálgica,

Dessa poesia de fracos diante da vida forte. A vida é força.

A vida é uma afirmação de heroísmos

[quotidianos,

De entusiasmos isolados de que nascem [mundos.

Lá vai passando uma mulher... Chove na [velha praça...

Pobre dessa poesia de doentes atrás de

[janelas!

Eu quero o sol na tua poesia e na dos teus

[amigos!

O Brasil é cheio de sol! O Brasil é cheio de [força!

É preciso criar a poesia do Brasil!'

Eu escutava, de olhos irônicos e mansos,
O mestre ardente das transformações

[próximas.

Por acaso, começou a chover docemente Na tarde monótona que se ia embora. Pela vidraça da minha saleta morta Ficamos a olhar a praça debaixo da chuva [lenta.

Ficamos em silêncio um tempo

[indefinido...

E lá embaixo passou uma mulher sob a

[chuva".

Não há como resumir aqui o modo como Luiza Franco Moreira destrincha as emaranhadas estratégias entre poesia e projeto político, dentro do pensamento de Cassiano Ricardo. Analisa construções de matrizes - como o mito de Martim Cererê -; o desenvolvimento que elas tomam na poesia do autor; a penetração e o alcance dessas formas junto ao público. Um ponto de grande interesse é a demonstração dos modos pelos quais Cassiano Ricardo transforma o mito paulista dos bandeirantes num instrumento ideológico nacional.

O livro acena para tantas perspectivas, que induz o desejo de novas pesquisas. Assim, por exemplo, sobre as ilustrações de Lívio Abramo para Marcha para o Oeste, cuja dinâmica do traço forte vem colorida por um sorriso irônico, que acompanham o texto de Meninos, Poetas \& Heróis; ou sobre o Monumento às Bandeiras, de Brecheret - pesado esforço de pedra que teve uma história tão longa - nos seus vínculos com a geopolítica proposta por Cassiano Ricardo. Com o estímulo provocado pela leitura desse livro novo e tão inteligente, surge também o desejo de saber mais sobre o poeta, sobre os caminhos que trilhou depois do Estado Novo. E, na medida em que a análise proposta por Luiza Franco Moreira é, antes de tudo, aquela das tramas ideológicas, brota ainda outro desejo: o de uma compreensão propriamente poética de Cassiano Ricardo, cuja invenção, de modo algum, é literariamente inferior ou indigna. 